\title{
A Study on the Factors Affecting Self-Concept of Children and Adolescents with Epilepsy
}

\author{
Su Hee Ha ${ }^{1}$, Hee-Yeon Choi ${ }^{1}$, Hyang Woon Lee ${ }^{2}$, and Eui-Jung Kim ${ }^{1}$ \\ ${ }^{1}$ Department of Psychiatry, College of Medicine, Ewha Womans University, Seoul, Korea \\ ${ }^{2}$ Department of Neurology, College of Medicine, Ewha Womans University, Seoul, Korea
}

\section{뇌전증 소아청소년 환아의 자아개념에 영향을 미치는 요인에 대한 연구}

\author{
하수희 ${ }^{1}$, 최희연 ${ }^{1}$, 이향운 ${ }^{2}$, 김의정 ${ }^{1}$ \\ 이화여자대학교 의과대학 정신건강의학교실, ${ }^{1}$ 이화여자대학교 의과대학 신경과학교실 ${ }^{2}$
}

\begin{abstract}
Objective: The purpose of this study was to investigate the impact of clinical and psychological factors on the self-concept of children and adolescents with epilepsy.

Methods: Children and adolescents with epilepsy ( $n=60$; age range=9-17 years) completed questionnaires about their epilepsy-related variables, self-concept, depressive symptoms, anxiety, family functions, and behavioral problems. The T-test and one-way analysis of variance were used to examine the variables affecting the total self-concept scores. To determine the independent variables by adjusting the significant variables, a stepwise regression analysis was performed.

Results: In the correlational analysis, age, depressive symptoms, anxiety, social problems, attention problems, and internalizing problems had significantly negative correlations with self-concept. On the other hand, IQ and family functions showed positive correlations with selfconcept. Age $(\beta=-0.177, \mathrm{p}=0.015)$, depressive symptoms $(\beta=-0.487, \mathrm{p}<0.001)$, anxiety $(\beta=-0.298, \mathrm{p}=0.008)$, and attention problems $(\beta=$ $-0.138, p=0.048$ ) were analyzed as independent factors to assess their impact on self-concept, and were found to account for $78.3 \%$ of the variance in self-concept by stepwise regression analysis.
\end{abstract}

Conclusion: Parents and clinicians should pay attention to improving the self-concept of children and adolescents with epilepsy, especially if they have problems with depression, anxiety, or attention.

Key Words: Epilepsy; Self concept; Child; Adolescent; Depression; Anxiety; Attention.

Received: June 19, 2017 / Revision: August 14, 2017 / Accepted: August 30, 2017

Address for correspondence: Eui-Jung Kim, Department of Psychiatry, College of Medicine, Ewha Womans University, 1071 Anyangcheon-ro, Yangcheongu, Seoul 07985, Korea

Tel: +82-2-2650-5164, Fax: +82-2-2650-2649, E-mail: christie@ewha.ac.kr

\section{서 론}

뇌전증은 소아기에 가장 흔한 만성 신경질환으로 한국에서 의 유병률은 1000 명 당 4.0명으로 추정되며, 특히 5 9세 사이 의 소아에서 1000 명 당 5.1 명으로 가장 높은 유병률을 보인 다. ${ }^{1)}$ 또한 20세 미만의 소아청소년에서는 나이가 어릴수록 활 동성 뇌전증의 비율이 높다는 것이 특징이다. ${ }^{1)}$ 뇌전증 환자 중 $30 \%$ 는 치료에 잘 반응을 하지 않는 난치성 간질로 진행하지 만 70\%에서는 완치가 가능할 정도로 비교적 약물로 치료가

This is an Open Access article distributed under the terms of the Creative Commons Attribution Non-Commercial License (http://creativecommons.org/licenses/by-nc/4.0) which permits unrestricted non-commercial use, distribution, and reproduction in any medium, provided the original work is properly cited.
잘 되는 질병임에도 불구하고, 소아기의 뇌전증은 발작의 조절 여부와 상관없이 소아청소년기의 정서적 어려움의 위험성을 증 가시킨다. ${ }^{2}$

소아기에 만성질환이나 장애가 있는 경우 정상 소아에 비해 성장하면서 정서 문제나 행동 장애의 위험성이 증가하게 되는 데, 특히 중추신경계 기능에 영향을 미칠 수 있는 뇌전증이나 뇌성마비와 같은 경우 더 낮은 학업적, 사회적 기능을 가질 위 험이 큰 것으로 보고되었다. ${ }^{3)}$ 소아청소년의 뇌전증은 경련발 작 외에도 여러 가지 정서, 인지, 행동적 문제를 동반하는데, 뇌 전증 소아의 $40 \%$ 에서 지적 장애, $33 \%$ 에서 $\mathrm{ADHD}, 21 \%$ 에서 자 폐 장애가 동반되며 이 외에도 우울장애, 불안장애와 같은 정 서적 문제, 행동적 문제를 보인다. ${ }^{4}$ 또한 청소년기는 신체적으 
로 성숙하고 인지적 능력이 성장하는 것뿐만 아니라 자아 정 체성의 확립이 중요한 발달 과업으로, 소아청소년기에 뇌전증 과 같은 만성질환이 있는 경우에는 자아개념(self-concept)에 도 부정적인 영향을 미치게 된다.)

자아개념은 자아존중감의 한가지 결정요인으로서, 소아가 자기 자신을 어떻게 보는지를 나타낸다. ${ }^{6}$ 자아개념은 환경에 대한 개인의 경험과 개인에게 중요한 의미를 가지는 타인으로 부터의 기대와 인식을 통해 형성되는 정체성의 중요한 측면으 로, 사회적 수용, 신체 능력 및 외모, 학업 능력과 같은 개인적 특성에 대한 평가를 포함하며 청소년 심리적 건강에 있어 중 요한 요소이다.) 이전 연구에서 뇌전증이 있는 소아청소년은 부정적인 자아개념을 형성할 위험성이 높다고 보고하였는 데, ${ }^{58)}$ 경련으로 인해 학교 수업 참여가 제한되고 학업 성취도 저하되며 사회적 적응에 부정적인 영향을 미쳐 현재 삶의 만 족감이 떨어지게 되고, ${ }^{9}$ 뇌전증 소아청소년의 부모는 과잉보호 나 활동에 과도한 제한을 함으로써 독립성의 획득이나 사회 적 발달을 저해할 수 있다. ${ }^{10}$ 또한 경련은 예측할 수 없고 갑자 기 발작 행동을 일으킬 수 있어 불안감을 야기시키고, 경련으 로 인한 외상뿐 아니라 내적으로 수치심과 불명예를 느낄 수 있어서, 경련 자체와 이로 인해 발생되는 상황이 소아청소년 스스로에게 낙인이 되고 또래로부터 사회적으로 격리되는 어 려움을 겪는다. 또한 장기적인 치료과정에 순응해야 하는 어 려움이 있어 뇌전증 소아청소년은 천식, 당뇨 등과 같은 다른 만성질환이 있는 소아청소년에 비해 더 부정적인 자아상과 사회적 문제를 갖게 된다. ${ }^{11,12)}$

본 연구는 궁극적으로는 뇌전증 소아청소년의 자아개념을 향상시키는 데 기여하고자, 일 대학병원에서 뇌전증으로 치료 를 받고 있는 소아청소년 환자를 대상으로 뇌전증 소아청소년 의 자아개념을 평가하고 자아개념에 영향을 미치는 요인들을 평가하였다.

\section{방 법}

\section{대 상}

본 연구는 일 대학병원 뇌전증 클리닉에서 뇌전증으로 진 단받고 외래 통원치료를 받는 소아청소년을 대상으로 하였다. 자가보고 설문지를 이해하고 작성할 수 있고, 자신의 자아개념 을 평가할 수 있는 만 9 세 이상 17세 이하를 대상으로 연구를 진행하였다. 한국판 웩슬러 지능검사(Korean-Wechsler Intelligence Scale)를 시행하여 지적 장애가 있는 경우 $(\mathrm{IQ}<70)$ 는 제외하였고, 신경과 전문의 및 정신건강의학과 소아청소년전 문의의 대상자 임상면담과 보호자 면담을 통해 뇌전증 이외의 일상생활에 영향을 줄 수 있을 정도의 심한 신경학적 장애가
있거나, 정신건강의학과적 질환 및 내과적 질환을 동반한 환 아도 제외하였다. 또한 두부손상의 병력이 있는 경우, 뇌 자기 공명영상(magnetic resonance imaging)에서 뇌 손상이 확인 되거나, 경련 증상이 조절되지 않는 심한 뇌전증 증상을 가진 경우에도 대상에서 제외되었다. 본 연구는 동 기관의 기관생명 윤리심의위원회(Institutional Review Board)의 승인을 받아 진행하였다(IRB No. 13-01A-05).

\section{평가 방법}

사회인구학적 특성(Socio-demographic factors) 및 뇌전증 관련 임상적 변인(Epilepsy-related variables)

환아 어머니의 교육 수준이나 가족의 수입에 대한 정보는 보 호자 보고를 통하여 수집되었다. 또한 대상자들의 의무기록 을 통하여 뇌전증의 발병 나이, 이환 기간, 경련의 빈도, 종류 및 원인, 복용하고 있는 항경련제의 개수에 대한 정보를 수집 하였다.

\section{자아개념 측정 질문지(Self-Concept Inventory, SCI)}

연구 대상자의 자아개념을 평가하기 위하여 10세 아동부터 고등학생까지 사용이 가능한 Song ${ }^{13)}$ 의 자아개념 검사를 요인 분석하여 재구성한 자아개념 측정 질문지(Self-Concept Inventory) $)^{14}$ 를 사용하였다. 일반자아, 학급 및 학업자아, 사회적 자아, 가족자아, 정서자아, 신체자아의 6가지 하위 척도로 이루 어져 있으며, 각 문항은 4점 Likert 척도로 각 차원별로 총점 이 높을수록 자아개념이 긍정적이라 평가할 수 있다.

\section{소아우울척도(Children's Depression Inventory, CDI)}

Kovacs와 Beck이 만 7 17세의 소아청소년 우울증의 인지 적, 정서적, 행동적 증상을 평가하기 위해 개발한 자기보고식 척도로, Beck의 성인용 우울척도를 연령에 맞게 수정한 것으 로 총 27문항으로 구성되어 있다. ${ }^{15)}$ 각 문항에 대한 3가지의 문장 중 자신의 상태를 가장 잘 표현하는 문장을 선택하도록 되어있으며 0 2점의 Likert 척도로 측정되어 최대 총점은 54 점이고 점수가 높을수록 우울 정도가 심하고 다양한 우울 증 상을 보이는 것을 나타낸다. 본 연구에서는 한국어판 소아우 울척도(Korean-Children's Depression Inventory, K-CDI ${ }^{16)}$ 을 사용하였다.

\section{아동발현불안척도(Revised Children's Manifest Anxiety Scale, RCMAS)}

만 6 19세 소아청소년의 불안 증상을 평가하기 위하여 Reynolds와 Richmond ${ }^{17)}$ 에 의해 수정 보완되어 사용되는 자 
가보고식 검사로, 쉽게 드러나지 않고 관찰될 수 없는 불안을 스스로 보고할 수 있다는 장점이 있다. 총 37개의 항목으로 28 개의 불안 항목과 9 개의 허구 항목으로 구성되어 있으며, 각 각의 항목은 자신이 어떻게 생각하고 느끼는지에 대하여 "예" 또는 "아니오" 중 선택하여 답하도록 되어 있다. 본 연구에서 는 한국어판 아동발현불안척도(Korean-Revised Children's Manifest Anxiety Scale, K-RCMAS)를 사용하였다. ${ }^{18)}$

\section{아동행동평가척도(Child Behavior Checklist, $\mathrm{CBCL}$ )}

Achenbach와 Edelbrock ${ }^{19}$ 에 의해 아동의 정서적, 행동적 문제를 평가하기 위하여 고안되었으며, 국내에서 Lee 등이이 표준화하였다. 아동기에 흔히 나타날 수 있는 핵심증상을 추 출하여 행동문제를 척도화하였으며 총 118 개의 항목으로 구 성되어 있다. 부모나 교사가 지난 6 개월 동안의 아동의 행동 문제에 대하여 3점 Likert 척도(0점-'전혀 없다', 1점='가끔 혹 은 때때로 그렇다', 2점='자주 혹은 매우 그렇다')로 평가하며 점수가 높을수록 문제 행동이 심각한 것으로 평가한다. 문제 행동증후군 척도는 우울/불안(anxious/depressed), 위축 (withdrawn), 신체증상(somatic complaints), 공격적 행동 (aggressive behavior), 비행(delinquent behavior), 사고 문제 (thought problems), 주의력 문제(attention problems), 사회적 문제(social problems)의 8개 소척도로 나뉘고, 우울/불안, 위 축, 신체증상은 내재화(internalizing) 문제로 평가되며 공격 적 행동과 비행은 외현화(externalizing) 문제로 평가된다. 본 연구에서는 원점수를 성별과 연령에 따라 변환시킨 $\mathrm{t}$ 점수를 사용하였다.

\section{가족적응력 및 결속력평가척도(Family Adaptability and Cohesion Evaluation Scale, FACES-III)}

Olson 등 ${ }^{21}$ 에 의해 개발된 척도로 가족의 적응력에 대한 10 개의 항목과, 가족의 결속력을 평가하는 10 개의 항목으로 이 루어져 있다. 각 1 5점으로 점수화되며 가족 적응력과 결속력 이 결합된 범주로 가족 기능을 정의하게 되고 점수가 높을수 록 가족 기능이 좋은 것으로 평가된다. 균형잡인(balanced), 중간 정도의(mid-range), 극단적인(extreme) 가족 유형으로 분류된다. 본 연구에서는 Yoon 등 22$)$ 이 신뢰도와 타당도를 분 석한 척도를 사용하였다.

\section{분 석}

총 62 명의 연구 참여자 중 자가보고 설문지의 답변이 충실하 지 않은 2 명을 제외하고 분석하였다. 뇌전증 소아청소년의 자 아개념과 각 변수 간의 연관성을 보기 위해 변수의 종류에 따라 독립 $\mathrm{t}$ 검정, 일원분산분석(analysis of variance), 피어슨 상관
분석(Pearson correlation)으로 단변량 통계 분석을 시행하였 다. 단변량 분석에서 자아개념과 통계적으로 의미 있는 변수 를 독립변수로 하여 자아개념에 독립적으로 영향을 미치는 변수를 찾기 위해 단계적 선형회기분석(stepwise regression analysis)을 시행하였다. 통계 분석은 Window용 Statistical Package for the Social Science version 20.0(IBM Corp., Armonk, NY, USA)을 이용하였고, 통계적 유의성은 $\mathrm{p}<0.05$ 에서 검정하였다.

\section{결 과}

\section{연구 대상자의 사회인구학적 특성 및 뇌전증 관련 임상적 변인}

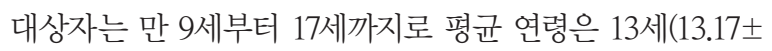

Table 1. Total self-concept score by socio-demographic and epilepsy-related variables

\begin{tabular}{|c|c|c|c|}
\hline & \multicolumn{2}{|c|}{ Total self-concept score } & \multirow{2}{*}{$\mathrm{p}$} \\
\hline & n (\%) & Mean \pm SD & \\
\hline \multicolumn{4}{|l|}{ Socio-demographic variables } \\
\hline Sex & & & 0.83 \\
\hline Male & $32(53.3)$ & $338.91 \pm 50.53$ & \\
\hline Female & $28(46.7)$ & $335.93 \pm 53.83$ & \\
\hline Maternal education & & & 0.12 \\
\hline$\leq$ middle school & $3(5.0)$ & $286.00 \pm 37.64$ & \\
\hline zhigh school & $30(50.0)$ & $333.50 \pm 54.32$ & \\
\hline$\geq$ college & $27(45.0)$ & $347.70 \pm 47.17$ & \\
\hline Family income (W, million) & & & 0.25 \\
\hline $\operatorname{Low}(\leq 2)$ & $10(16.7)$ & $312.80 \pm 48.07$ & \\
\hline Middle $(2-5)$ & $42(70.0)$ & $343.12 \pm 50.15$ & \\
\hline $\operatorname{High}(5 \leq)$ & $8(13.3)$ & $339.00 \pm 61.10$ & \\
\hline \multicolumn{4}{|l|}{ Epilepsy-related variables } \\
\hline Seizure frequency (past year) & & & 0.92 \\
\hline Seizure-free & $20(33.3)$ & $336.60 \pm 44.09$ & \\
\hline$\geq 1$ & $40(66.7)$ & $337.98 \pm 55.59$ & \\
\hline Type of seizure & & & 0.68 \\
\hline Generalized & $31(51.7)$ & $343.10 \pm 48.71$ & \\
\hline Complex partial & $11(18.3)$ & $329.09 \pm 55.63$ & \\
\hline Others & $18(30.0)$ & $333.06 \pm 55.97$ & \\
\hline Etiology of seizures & & & 0.07 \\
\hline Idiopathic & $18(30.0)$ & $351.89 \pm 50.69$ & \\
\hline Cryptogenic & $28(46.7)$ & $328.32 \pm 51.45$ & \\
\hline Familial & $6(10.0)$ & $372.17 \pm 45.94$ & \\
\hline Symptomatic & $8(13.3)$ & $311.38 \pm 43.17$ & \\
\hline Number of antiepileptic drugs & & & 0.08 \\
\hline None & $2(3.3)$ & $316.00 \pm 11.31$ & \\
\hline Monotherapy & $55(91.7)$ & $342.25 \pm 50.47$ & \\
\hline Ditherapy & $2(3.3)$ & $271.00 \pm 41.01$ & \\
\hline Polytherapy & $1(1.7)$ & 253.00 & \\
\hline
\end{tabular}

SD: standard deviation 
2.58)였으며 총 60 명 중 남아가 32명으로 여아에 비해 더 많았 으나 성별에 따른 자아개념 총점의 차이는 없었다. 또한 환아 어머니의 교육 수준이나 경제적 수준에 따른 자아개념 총점의 유의한 차이도 없었다.

뇌전증이 시작된 평균 나이는 9 세 $(9.20 \pm 3.60)$ 로 대상자들의 평균 뇌전증 이환 기간은 3 년(2.76 \pm 2.08$)$ 이었다. 뇌전증 소아 청소년 중 1년 이내 경련이 있었던 경우인 활동성 뇌전증(active epilepsy) 환아는 전체 40 명이었으나 비활동성 뇌전증 소아청 소년과 비교했을 때 자아개념 총점의 유의한 차이는 없었다. 또한 경련의 종류나 원인에 따른 차이도 없었으며 복용하고 있 는 항경련제 개수에 따른 자아개념 총점의 통계적 차이는 없 었다(Table 1).

\section{자아개념과 심리적 요인, 행동문제, 가족기능과의 상관성}

자아개념 총점은 나이 $(\mathrm{r}=-0.493, \mathrm{p}<0.001)$ 와는 중등도의 음의 상관관계를 보였으며, $\mathrm{IQ}(\mathrm{r}=0.392, \mathrm{p}=0.003)$ 와는 중등도 의 양의 상관관계를 보였다. 자아개념 총점과 심리적 요인과의 상관관계는 $\mathrm{CDI}$ 총점 $(\mathrm{r}=-0.835, \mathrm{p}<0.001)$ 과는 강한 음의 상 관관계를 보였고, $\mathrm{RCMAS}$ 총점 $(\mathrm{r}=-0.768, \mathrm{p}<0.001)$ 과도 강한 음의 상관관계를 보였다. 자아개념 아형별로 보았을 때, $\mathrm{CDI}$ 와 는 일반적 자아개념, 심리적 자아개념, 신체적 자아개념, 가족 자아개념, 학교 자아개념, 사회적 자아개념 순서로 강한 음의 상관관계를 보였으며, RCMAS와는 신체적 자아개념, 일반적 자아개념, 심리적 자아개념, 가족 자아개념, 사회적 자아개념, 학교 자아개념 순서로 강한 음의 상관관계를 보였다. 자아개념 총점은 가족기능 총점 $(r=0.441, p<0.001)$ 과 중등도의 양의 상관 관계를 보였고, 행동문제 중에서 주의집중 문제 $(\mathrm{r}=-0.467, \mathrm{p}<$ $0.001)$ 와 사회적 미성숙 문제 $(\mathrm{r}=-0.374, \mathrm{p}=0.003)$ 와는 중등도의 음의 상관관계를 보였고 내재화 문제 $(r=-0.318, p=0.013)$ 와는 경한 음의 상관관계를 보였다(Table 2).

\section{자아개념에 독립적으로 영향을 미치는 요인}

자아개념 총점과 독립적으로 연관성을 가지는 변인을 분석 하기 위해 자아개념과 연관성을 보였던 나이, IQ, CDI, RCMAS, 가족기능과 Child Behavior Checklist 중 주의집중 문제, 사 회적 미성숙 문제, 내재화 문제를 독립변수로 하여 단계적 선 형회기분석을 시행하였다. 나이, $\mathrm{CDI}, \mathrm{RCMAS}$, 주의집중 문 제가 자아개념 총점과 독립적인 연관성을 보였고, 이 변인들의 자아개념 총점에 대한 설명력은 78\%였다(Table 3).

\section{고 찰}

본 연구는 뇌전증 소아청소년 환아의 자아개념에 영향을 미
치는 요인을 평가한 연구로, 나이가 어릴수록, 인지기능이 좋 을수록, 우울증상 및 불안증상이 적을수록, 가족 기능이 좋 을수록 자아개념이 높았다. 또한 행동문제 중 사회적 미성숙, 주의집중, 내재화 문제가 적을수록 자아개념이 높았다. 이 중 나이, 우울증상, 불안증상, 주의집중 문제가 자아개념과 독립 적으로 유의한 연관성을 나타내었다.

본 연구 대상자는 스스로 자아개념을 평가할 수 있는 만 9세 이상의 소아부터 17세 청소년으로, 나이가 어릴수록 자아개념 총점이 높았다. 어린아이들은 자신에 대한 고유의 개념에 대 해서 복잡한 개념을 형성할 수 없어 자신의 능력에 대한 비현 실적인 인식이 높아지기 때문에 상대적으로 높은 수준의 자 아개념을 가지고 있는 것처럼 보일 수 있다. ${ }^{23)}$ 어린아이의 과도 하게 높은 자아개념은 인지발달로 자신에 대한 이해를 하게 되고 다른 사람들과 사회적 비교를 통해 자신의 약점을 알면 서 후기 소아기와 청소년기에 스스로의 능력에 대해 더 정확하 게 인식해 가면서 성숙해간다. ${ }^{24)}$ 뇌전증은 대부분 소아기에 발 생하여 만성적인 경과를 갖게 되는 질환으로, 발달 시기 동안 신체적 문제 뿐만 아니라 뇌전증으로 인한 부가적인 부담을 갖게 되어 자아개념이 손상될 수 있는 위험성이 크다. 경련 자 체와 항전간제의 부작용은 학습능력을 저하시키고 학업 순응 도를 떨어뜨릴 수 있으며, ${ }^{25}$ 뇌전증은 다른 만성질환보다 더 부정적인 낙인을 갖게 되는 경우가 많아 뇌전증 소아청소년 이 사회적으로 수용되는 데 방해가 될 수 있어 뇌전증 소아청 소년은 당뇨, 천식과 같은 다른 만성질환을 가진 소아청소년 에 비해서 더 낮은 자아개념을 가진다고 보고되었다. ${ }^{5,8)}$

인지기능이 좋을수록 자아개념이 높았는데 인지 결함은 뇌 전증 환자에서 가장 중요한 문제 중 하나로 인지 감퇴, 정보처 리 속도 저하, 반응 속도 저하, 주의력 저하, 기억력 결함이 주 로 나타난다. ${ }^{26,27)}$ 뇌전증 환자의 절반에서 학습의 어려움이 보 고되었는데 ${ }^{28)}$ 경련이 정보의 장기저장에 영향을 미치고 야간 발작은 수면을 방해해서 기억의 강화를 저해할 수 있어서 학업 성취에 영향을 미친다. 소아청소년은 학교에서의 생활과 학업 이 중요한 발달과제이므로, 특히 소아 뇌전증 환아에서 지능, 집행기능, 언어, 정신운동속도 등의 인지기능 문제를 빨리 평 가하고 ${ }^{29}$ 경련을 잘 조절하는 것이 장기적으로 인지 결함이 누 적되는 것을 예방하는 중요한 방법이다. ${ }^{30)}$ 또한 인지기능은 학 교 생활과 같은 사회 적응을 예측할 수 있는 요소로서, ${ }^{31)}$ 뇌전 증 환아의 인지기능이 좋을수록 학업 성취도 및 학교 적응에 유리하므로 자아개념도 향상될 수 있다.

뇌전증 소아청소년의 자아개념에 가장 영향을 많이 미치는 요인은 우울증상, 불안과 같은 심리적 요인으로 우울증상 및 불안이 심할수록 자아개념이 낮았다. 특히 우울증상은 독립 적으로도 뇌전증 소아청소년의 자아개념에 가장 큰 연관성을 


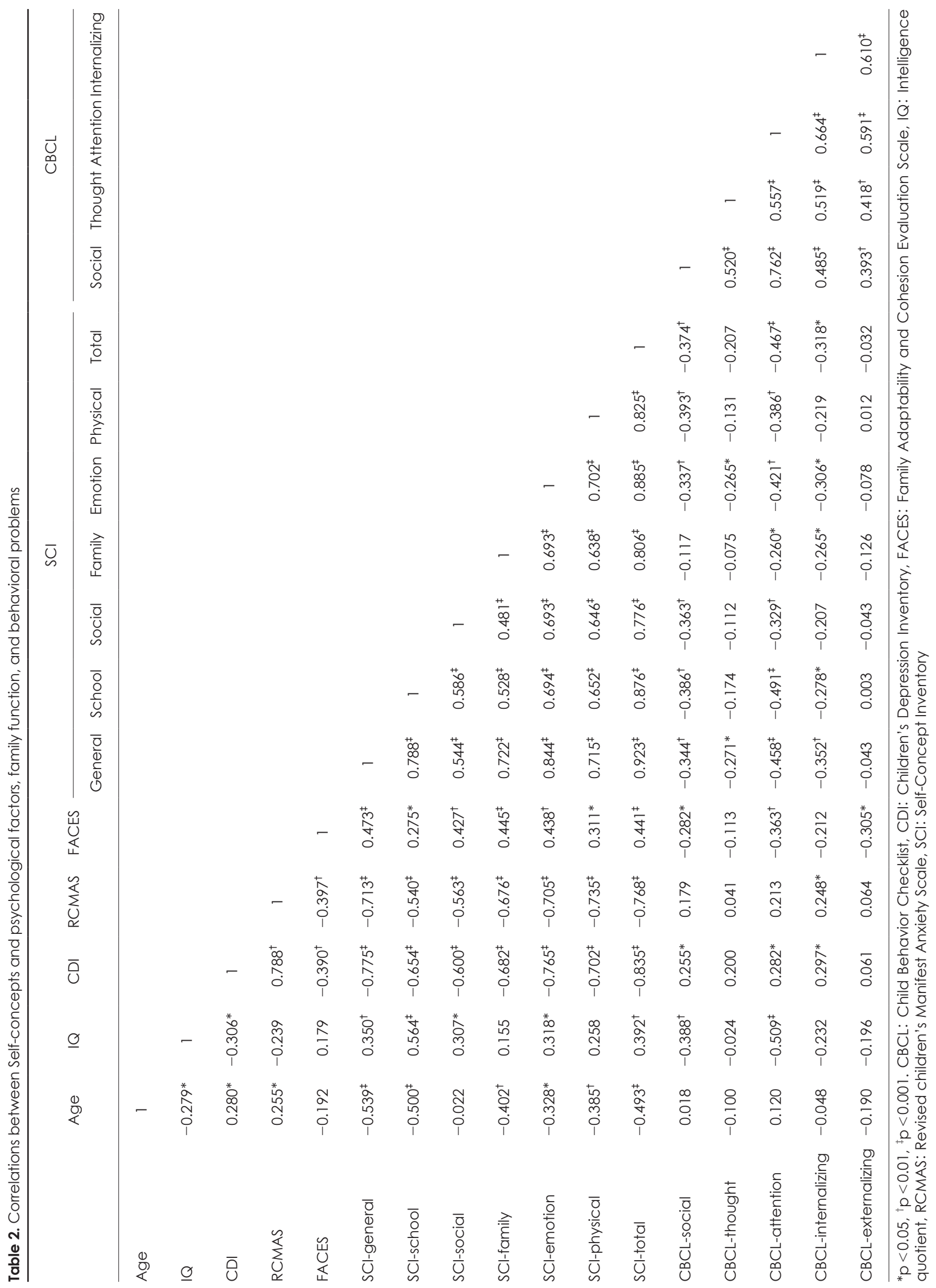


Table 3. The stepwise regression analysis for significant predictors of the self-concepts

\begin{tabular}{|c|c|c|c|c|c|c|}
\hline & $\mathrm{B}$ & SE & $\beta$ & $t$ & $\mathrm{p}$ & VIF \\
\hline \multirow[t]{2}{*}{ CDI } & -6.138 & 0.537 & -0.846 & -11.431 & 0.000 & 1.000 \\
\hline & \multicolumn{6}{|c|}{ Adjusted $R^{2} 0.710$} \\
\hline CDI & -4.216 & 0.844 & -0.581 & -4.997 & 0.000 & 2.805 \\
\hline \multirow[t]{2}{*}{ RCMAS } & -2.305 & 0.812 & -0.330 & -2.839 & 0.006 & 2.805 \\
\hline & \multicolumn{6}{|c|}{ Adjusted $R^{2} 0.745$} \\
\hline CDI & -3.808 & 0.816 & -0.525 & -4.666 & 0.000 & 2.915 \\
\hline RCMAS & -2.134 & 0.773 & -0.306 & -2.760 & 0.008 & 2.825 \\
\hline \multirow[t]{2}{*}{ Age } & -3.809 & 1.477 & -0.187 & -2.578 & 0.013 & 1.207 \\
\hline & \multicolumn{6}{|c|}{ Adjusted $R^{2} 0.770$} \\
\hline CDI & -3.537 & 0.803 & -0.487 & -4.403 & 0.000 & 2.998 \\
\hline RCMAS & -2.083 & 0.751 & -0.298 & -2.775 & 0.008 & 2.829 \\
\hline Age & -3.615 & 1.437 & -0.177 & -2.516 & 0.015 & 1.213 \\
\hline \multirow[t]{2}{*}{ CBCL-attention problems } & -0.692 & 0.342 & -0.138 & -2.025 & 0.048 & 1.138 \\
\hline & \multicolumn{6}{|c|}{ Adjusted $R^{2} 0.783$} \\
\hline
\end{tabular}

B: unstandardized coefficient, CBCL: Child Behavior Checklist, CDI: Children's Depression Inventory, RCMAS: Revised children's Manifest Anxiety Scale, SE: standard error, VIF: variance inflation factor

보였다. 뇌전증 청소년과 대조군을 비교한 연구에서 뇌전증 청 소년은 더 높은 우울증과 사회불안 증상을 보였고 ${ }^{32}$ 우울증 은 33\%, 불안장애는 49\%에서 나타난다고 보고되었는데, ${ }^{33)}$ 뇌 전증 소아의 $45 \%$ 에서 뇌전증이 발생하기 전에 불안, 우울증, 주의력 결핍 장애와 같은 정신심리적 문제가 선행되었다는 것 은 신경생물학적 요소가 관여하고 있음을 시사한다. ${ }^{34)}$ 뇌전증 의 경험으로 인한 낙인과 차별, 언제 경련이 발생할지 모른다 는 불확실성과 경련을 예측하고 조절할 수 없다는 경련의 특 성이 우울감 및 무력감을 느끼게 하고 불안감을 증가시킬 수 있다. 또한 뇌전증 환아의 부모는 환아를 과잉보호하는 경향 이 있는데, 이는 우울 및 불안 증상이 발생하는 데 심리적으로 영향을 줄 수 있으며,5) 이러한 심리적 요인은 부정적인 자아 개념이 형성되는 데 영향을 미칠 수 있다.

본 연구에서 가족기능은 자아개념과 중등도의 양의 상관관 계를 보였는데, 자아개념 총점뿐만 아니라 자아개념의 모든 아형에서 가족기능이 좋을수록 자아개념이 높아지는 결과를 보였다. 이는 만 7 18세의 뇌전증 소아청소년과 정상군의 자 아개념을 비교한 연구에서 낮은 자아개념은 부정적인 가족기 능과 연관성을 보인 결과와 같은 맥락이다. ${ }^{36}$ 가족의 기능은 만 성질환을 가진 소아의 적응에 중요한 역할을 하는데, 뇌전증 소아의 적응과 인지 및 행동 기능에 중요한 영향을 미치며,37) 기능이 좋은 가족은 자아개념에 대한 뇌전증의 부정적 영향 을 개선할 수 있고, 치료의 순응도를 향상시키고, 전반적인 삶 의 질을 높이게 한다. ${ }^{38)}$

뇌전증 소아청소년의 행동문제 중에서 사회적 미성숙, 주의 집중, 내재화 문제가 낮을수록 자아개념이 높았고, 이 중 주의 집중 문제는 독립적으로 뇌전증 소아청소년의 자아개념과 연
관성을 보였다. 주의력과 집중력의 문제는 뇌전증 소아에서 매 우 흔한 증상으로 attention-deficit hyperactivity disorder (ADHD)의 경우 동반이환률이 28 70\%에까지 이르며, ${ }^{39)}$ 기 저의 뇌기능부전, 반복되는 경련의 만성적인 영향, 항전간제 약물의 영향 등이 영향을 주는 것으로 알려져 있다. ${ }^{40}$ 뇌전증 소아청소년을 정상군과 비교했을 때 뇌전증 소아청소년의 $\mathrm{ADHD}$ 증상, 특히 부주의 증상은 부정적인 자아개념과 연관 성을 보였다. ${ }^{38)}$

이전 연구에서 발작 빈도가 높거나 증상이 심한 경우 뇌전 증 소아청소년의 낮은 자아개념과 연관이 있다는 보고가 있 었으나, ${ }^{32)}$ 본 연구에서는 발작 빈도, 발작 종류와 같은 뇌전증 과 관련된 요인들에 따른 자아개념의 차이는 유의하지 않았 다. 복용하는 약물의 수에 따른 자아개념의 차이도 유의하지 않았는데 약물의 수가 많은 것은 낮은 자아개념과 연관성이 있다는 이전의 연구결과에서는 항전간제가 신체적 또는 인지 적 부작용을 야기시켜서 자아개념을 손상시킬 수 있고, 약을 먹는 것 자체가 다른 친구들과 '다르다'고 느끼게 하거나 '정상' 이 되기 위해 약물에 의존한다고 받아들이게 되어 자아개념 에 영향을 미칠 수 있다고 설명하였다. ${ }^{38)}$

본 연구의 제한점은 먼저 일 대학병원 뇌전증 소아청소년을 대상으로 하였기 때문에 연구 결과를 일반화시키기에는 한계 가 있다. 또한 심리, 행동 문제에 대하서 자기보고식 검사로 평 가하였기 때문에 객관적인 평가가 동반되지 않았다는 점이 제 한점이다. 하지만 신경과와 정신건강의학과 소아청소년 전문 의 면담, 지능검사, 뇌자기공명영상을 시행하여서 뇌전증 소아 청소년에 많이 나타날 수 있고 심리 및 행동문제에 영향을 미 칠 수 있는 인지기능 문제와 기타 신경학적, 정신건강의학적 문 
제를 최대한 배제하였다.

여러 제한점에도 불구하고 본 연구는 일 대학병원 뇌전증 클리닉에서 통원치료를 하고 있는 소아청소년을 대상으로 뇌 전증 환아의 자아개념을 평가하였고, 자아개념에 영향을 미 치는 요인을 분석하였다. 향후 정상 소아청소년의 자아개념을 같이 평가하고 비교하는 연구가 이루어져야 할 것이다.

뇌전증 소아청소년의 자아개념을 향상시키는 것은 치료에 대한 순응도를 높여서 치료 성공률과 예후를 향상시킬 뿐만 아니라, ${ }^{41)}$ 만성질환을 겪으면서 발생할 수 있는 신체적, 심리적, 사회적 문제들에 대해 더 잘 적응하도록 할 수 있다. 따라서 뇌전증 소아청소년의 우울 및 불안과 같은 심리적 문제와 주 의력 문제를 초기에 평가하고, 빠른 치료적 개입을 위한 실제 적인 방법이 모색되어야 할 것으로 생각된다. 또한 뇌전증에 대한 지식이 부족할수록 우울증상이 높고, 자아존중감이 낮 고, 사회불안이 높으므로, ${ }^{32)}$ 뇌전증 소아청소년과 부모에게 뇌 전증에 대한 올바른 지식을 알게 해주는 교육과, 우울증, 불안 장애, 주의력 문제의 증상과 잠재적 위험성에 대한 교육이 병 행되어야 하겠다.

\section{결 론}

본 연구에서 뇌전증 소아청소년 환아의 나이가 어릴수록, 인 지기능이 좋을수록, 우울증상 및 불안증상이 적을수록, 가족 기능이 좋을수록 자아개념이 높았고, 행동문제 중 사회적 미 성숙, 주의집중, 내재화 문제가 적을수록 자아개념이 높았다. 이 중 나이, 우울증상, 불안증상, 주의집중 문제가 자아개념 과 독립적으로 유의한 연관성을 나타내었으므로, 뇌전증 소 아청소년의 인지적, 심리적 문제에 대해 치료진이 치료 초기 부터 지속적인 관심을 갖고 주의 깊게 관찰해서 빠른 평가와 치료적 개입이 실질적으로 이루어져야 할 것이다.

중심 단어:뇌전증; 자아개념; 소아; 청소년; 우울; 불안; 주의집중.

\section{Conflicts of Interest}

The authors have no financial conflicts of interest.

\section{REFERENCES}

1) Kim DW, Lee SY, Chung SE, Cheong HK, Jung KY; Korean Epilepsy Society. Clinical characteristics of patients with treated epilepsy in Korea: a nationwide epidemiologic study. Epilepsia 2014;55:67-75.

2) Sbarra DA, Rimm-Kaufman SE, Pianta RC. The behavioral and emotional correlates of epilepsy in adolescence: a 7-year followup study. Epilepsy Behav 2002;3:358-367.

3) Pinquart M, Teubert D. Academic, physical, and social functioning of children and adolescents with chronic physical illness: a metaanalysis. J Pediatr Psychol 2012;37:376-389.
4) Reilly C, Atkinson P, Das KB, Chin RF, Aylett SE, Burch V, et al. Neurobehavioral comorbidities in children with active epilepsy: a population-based study. Pediatrics 2014;133:e1586-1593.

5) Austin JK. Comparison of child adaptation to epilepsy and asthma. J Child Adolesc Psychiatr Ment Health Nurs 1989;2:139-144.

6) Russo RN, Goodwin EJ, Miller MD, Haan EA, Connell TM, Crotty M. Self-esteem, self-concept, and quality of life in children with hemiplegic cerebral palsy. J Pediatr 2008;153:473-477.

7) Swann WB Jr, Chang-Schneider C, Larsen McClarty K. Do people's self-views matter? Self-concept and self-esteem in everyday life. Am Psychol 2007;62:84-94.

8) Hoare P, Mann H. Self-esteem and behavioural adjustment in children with epilepsy and children with diabetes. J Psychosom Res 1994;38:859-869.

9) Jalava M, Sillanpää M, Camfield C, Camfield P. Social adjustment and competence 35 years after onset of childhood epilepsy: a prospective controlled study. Epilepsia 1997;38:708-715.

10) Seiffge-Krenke I. Chronic disease and perceived developmental progression in adolescence. Dev Psychol 1998;34:1073-1084.

11) Kobau R, Price P. Knowledge of epilepsy and familiarity with this disorder in the U.S. population: results from the 2002 HealthStyles Survey. Epilepsia 2003;44:1449-1454.

12) Cheung C, Wirrell E. Adolescents' perception of epilepsy compared with other chronic diseases: "through a teenager's eyes". J Child Neurol 2006;21:214-222.

13) Song IS. The identification and measurement of self-concept. J Educ Eval 2004;17:1-25.

14) Han SB. The relationship between children's self-concepts and family systems as analyzed by the circumplex model. Korean J Child Stud 1992;13:145-160.

15) Kovacs M. The Children's Depression, Inventory (CDI). Psychopharmacol Bull 1985;21:995-998.

16) Cho SC, Lee YS. Development of the Korean form of the Kovacs' Childeren's Depression Inventory. J Korean Neuropsychiatr Assoc 1990;29:943-956.

17) Reynolds CR, Richmond BO. Factor structure and construct validity of "what I think and feel": The Revised Children's Manifest Anxiety Scale. J Pers Assess 1979;43:281-283.

18) Choi JS, Cho SC. Assessment of Anxiety in Children. J Korean Neuropsychiatr Assoc 1990;29:691-702.

19) Achenbach TM, Edelbrock CS. Manual for the Child Behavior Checklist and Revised Child Behavior Profile. Burlington, VT: Dept. Psychiatry, University of Vermont;1983.

20) Lee HL, Oh KJ, Hong KE, Ha EH. Clinical validity study of Korean CBCL through item analysis. J Korean Acad Child Adolesc Psychiatry 1991;2:138-149.

21) Olson DH, Portner J, Lavee Y. FACES III. Family Social Science. St. Paul, MN: University of Minnesota;1985.

22) Yoon BB, Lee HR, Kwak KW, Oh MK, Lim JH, Lee KR. A study of reliability and validity of FACES III. Korean J Fam Med 1990;11:817.

23) Harter S, Pike R. The pictorial scale of perceived competence and social acceptance for young children. Child Dev 1984;55:1969-1982.

24) Marsh HW, Craven R, Debus R. Structure, stability, and development of young children's self-concepts: a multicohort-multioccasion study. Child Dev 1998;69:1030-1053.

25) Shields N, Loy Y, Murdoch A, Taylor NF, Dodd KJ. Self-concept of children with cerebral palsy compared with that of children without impairment. Dev Med Child Neurol 2007;49:350-354.

26) Moore PM, Baker GA. The neuropsychological and emotional consequences of living with intractable temporal lobe epilepsy: implications for clinical management. Seizure 2002;11:224-230.

27) Helmstaedter C, Kurthen M, Lux S, Reuber M, Elger CE. Chronic epilepsy and cognition: a longitudinal study in temporal lobe epilepsy. Ann Neurol 2003;54:425-432. 
28) de Boer HM, Mula M, Sander JW. The global burden and stigma of epilepsy. Epilepsy Behav 2008;12:540-546.

29) Hermann B, Jones J, Sheth R, Dow C, Koehn M, Seidenberg M. Children with new-onset epilepsy: neuropsychological status and brain structure. Brain 2006;129(Pt 10):2609-2619.

30) Aldenkamp A, Arends J. The relative influence of epileptic EEG discharges, short nonconvulsive seizures, and type of epilepsy on cognitive function. Epilepsia 2004;45:54-63.

31) Caplan R, Sagun J, Siddarth $P$, Gurbani $S$, Koh $S$, Gowrinathan $R$, et al. Social competence in pediatric epilepsy: insights into underlying mechanisms. Epilepsy Behav 2005;6:218-228.

32) Baker GA, Spector S, McGrath Y, Soteriou H. Impact of epilepsy in adolescence: a UK controlled study. Epilepsy Behav 2005;6:556562.

33) Ekinci O, Titus JB, Rodopman AA, Berkem M, Trevathan E. Depression and anxiety in children and adolescents with epilepsy: prevalence, risk factors, and treatment. Epilepsy Behav 2009;14:8-18.

34) Jones JE, Watson R, Sheth R, Caplan R, Koehn M, Seidenberg M, et al. Psychiatric comorbidity in children with new onset epilepsy. Dev Med Child Neurol 2007;49:493-497.

35) Ferrari M, Matthews WS, Barabas G. The family and the child with epilepsy. Fam Process 1983;22:53-59.

36) Ekinci O, Isik U, Gunes S, Yildirim C, Killi Y, Guler G. Self-concept in children and adolescents with epilepsy: the role of family functioning, mothers' emotional symptoms and ADHD. Brain Dev 2016; 38:714-722.

37) Oostrom KJ, van Teeseling H, Smeets-Schouten A, Peters AC, Jennekens-Schinkel A; Dutch Study of Epilepsy in Childhood (DuSECh). Three to four years after diagnosis: cognition and behaviour in children with 'epilepsy only'. A prospective, controlled study. Brain 2005;128(Pt 7):1546-1555.

38) Lee A, Hamiwka LD, Sherman EM, Wirrell EC. Self-concept in adolescents with epilepsy: biological and social correlates. Pediatr Neurol 2008;38:335-339.

39) Berl MM, Terwilliger V, Scheller A, Sepeta L, Walkowiak J, Gaillard WD. Speed and complexity characterize attention problems in children with localization-related epilepsy. Epilepsia 2015;56:833-840.

40) Dunn DW, Kronenberger WG. Childhood epilepsy, attention problems, and ADHD: review and practical considerations. Semin Pediatr Neurol 2005;12:222-228.

41) Austin JK, Huberty TJ. Development of the Child Attitude Toward Illness Scale. J Pediatr Psychol 1993;18:467-480. 